\title{
Evolución de la responsabilidad civil en el derecho argentino y español
}

\section{POR BELÉN MASCI $(*)$}

\begin{abstract}
Sumario: I. Introducción.- II. Primera etapa: no hay responsabilidad sin culpa.- III. Segunda etapa: responsabilidad objetiva.- IV. Tercera etapa: necesidad de unificación de la responsabilidad civil.- V. Recapitulación.- VI. Cuarta etapa: unificación de la responsabilidad contractual y extracontractual en Argentina: una deuda del legislador español.- VII. Conclusiones.- VIII. Bibliografía.
\end{abstract}

Resumen: la responsabilidad civil es un tópico que acompaña al hombre en su evolución, a la par de sus necesidades, de su vida y de su concepto de justicia. Dicha metamorfosis será estudiada navegando de manera comparativa por las aguas del derecho argentino y las del derecho español, viendo cómo ambos avanzan en igual sentido hasta cierto punto de disparidad. Tanto el Código Civil argentino como el español siguen el sistema romano-germánico teniendo como fuente el modelo francés, en este sentido se visualizará que ambos han dividido a la responsabilidad en contractual y extracontractual. La aclamación de una Teoría General de la Obligación aplicable a ambas órbitas se ha producido en ambos países, sin embargo, en Argentina ese pedido fue recepcionado por el Código Civil y Comercial que entró en vigor en agosto 2015; ello es sin dudas la asignatura pendiente del derecho español. Palabras claves: responsabilidad civil - unificación - contractual - extra
contractual

\section{The evolution of civil responsibility in Argentinean and Spanish law}

Abstract: civil responsibility is a topic that accompanies man in his evolution and has precisely evolved along with it, along with his needs, his life and his concept ofjustice. This metamorphosis will be studied navigating comparatively through the waters of Argentinean and Spanish law, seeing how both advance in the same direction to a certain point of disparity. Both, the civil code of Argentina and the Spanish

(*) Abogada, Universidad Nacional de La Plata. Esp. en Derecho Procesal Profundizado, Universidad Notarial Argentina. Esp. en Contratos y Daños, Universidad de Salamanca, España. Prof. Derechos Reales, Universidad Nacional del Noroeste de Buenos Aires. 
follow the Roman-Germanic system having as source the French model, in this sense it will be visualized that both have divided the Responsibility in Contractual and Non contractual. The acclamation of a General Theory of Obligation applicable to both orbits has occurred in both countries, however in Argentina that request was received by the New Civil and Commercial Code that came into force from August 2015; this is undoubtedly the pending subject of Spanish law.

\section{Keywords: civil responsibility - unification - contractual - non contractual}

\section{Introducción}

La responsabilidad civil es sin hesitación uno de los temas más importantes de nuestro derecho. Es un tópico que acompaña al hombre en su evolución dentro de la sociedad y ha precisamente evolucionado a la par de este, a la par de sus necesidades, de su vida y de su concepto de justicia. Los sistemas jurídicos vienen a dar un orden social en el cual aparece el "deber de responder" cuando la conducta de los individuos se traduce en actos unilaterales o bilaterales que producen una modificación en el mundo exterior y esa alteración menoscaba derechos. "La responsabilidad civil comporta siempre un deber de dar cuenta a otro del daño que se le ha causado" (Bustamante Alsina, 1991, p. 67). "Consiste en reparar, por medio de una indemnización pecuniaria, el daño que se ha causado a otros, de manera que ser civilmente responsable significa 'estar obligado a reparar por medio de una indemnización, un perjuicio sufrido por otras personas'” (Trigo Represas, 1992, tomo II, p. 365).

La evolución de la responsabilidad civil a la que hiciera referencia es precisamente el objeto de este trabajo. Se buscará estudiar la metamorfosis que la misma ha sufrido en sus fundamentos navegando de manera comparativa por las aguas del derecho argentino y las del derecho español, viendo cómo ambos avanzan en igual sentido hasta cierto punto de disparidad. Tanto el código civil argentino como el español siguen el sistema romano-germánico teniendo como fuente el modelo francés, en este sentido se visualizará que ambos han dividido a la responsabilidad civil en contractual y extracontractual. La discusión en torno a si la Responsabilidad civil es una sola con dos órbitas o se trata de dos tipos de responsabilidades distintas, se ha producido en ambos regímenes jurídicos, ya que ambos códigos fueron legislados trayendo normas específicas para una y otra responsabilidad. La aclamación de una Teoría General de la Obligación se ha producido en ambos países, sin embargo, en Argentina ese pedido fue recepcionado por el Nuevo Código Civil y Comercial que entró en vigor desde agosto de 2015; ello es sin dudas la asignatura pendiente del derecho español para que el mismo tenga un derecho privado constitucionalizado. 
EVOLUCIÓN DE LA RESPONSABILIDAD CIVIL EN EL DERECHO ARGENTINO Y ESPAÑOL

- BELÉn MASCI (PP. 99-116)

\section{Primera etapa: no hay responsabilidad sin culpa}

Nuestro máximo legislador, Vélez Sarsfield, siguiendo al código francés va a estructurar a la responsabilidad civil bajo la idea de la culpa. Sin culpa no hay responsabilidad. La responsabilidad es subjetiva. Es así como nuestro Código Civil receptó el postulado "no hay responsabilidad sin culpa" en su antiguo artículo 1067 "no habrá acto ilícito punible para los efectos de este Código (...) sin que a sus agentes se le pueda imputar dolo, culpa o negligencia". Con esa fórmula queda en claro que en el sistema de Vélez no había responsabilidad posible sin esa calificación reprensible del comportamiento del responsable: no basta una contradicción material entre la conducta del sujeto y lo querido o permitido por la ley, es indispensable que promedie una voluntad reprochable a la que sea dable calificar como culpable "lato sensu". También denotó la adquisición de aquel postulado en su artículo 1109, que expresaba que: "Todo el que ejecuta un hecho, que por su culpa o negligencia ocasiona un daño a otro, está obligado a la reparación del perjuicio. Esta obligación es regida por las mismas disposiciones relativas a los delitos del derecho civil". En su ámbito contractual, asimismo, hacía mención a la culpa como eje del sistema en su artículo 512, que establecía "La culpa del deudor en el cumplimiento de la obligación consiste en la omisión de aquellas diligencias que exigiere la naturaleza de la obligación, y que correspondiesen a las circunstancias de las personas, del tiempo y del lugar".

En el régimen español, su legislador en 1889 adoptó igual premisa, estructurando su sistema de responsabilidad en el principio de la culpa. Este fue receptado en el Código Civil Español para la responsabilidad extracontractual en su artículo 1902, que establece: "El que por acción u omisión causa daño a otro, interviniendo culpa o negligencia, está obligado a reparar el daño causado". Y para el ámbito de la responsabilidad contractual lo encontramos en su artículo 1101: "Quedan sujetos a la indemnización de los daños y perjuicios causados los que en el cumplimiento de sus obligaciones incurrieren en dolo, negligencia o morosidad, y los que de cualquier modo contravinieren al tenor de aquéllas".

Establecida la responsabilidad civil en ambos códigos civiles (argentino y español) bajo fundamentos subjetivos, la doctrina nacional y extranjera se debatió entre el dilema de la dualidad o unidad de culpa: ¿existe una culpa contractual versus una culpa extracontractual?, o bien, ¿la culpa es una sola aplicable a dos regímenes distintos? La expresión unidad o dualidad de la culpa es un resabio de la doctrina francesa clásica que circunscribía toda responsabilidad al concepto de la culpa y de allí el porqué de una culpa contractual y una culpa aquiliana.

A) Dualidad de Culpas (culpa contractual y culpa extracontractual): para esta concepción - considerada clásica- la culpa es una noción equívoca que engloba dos conceptos distintos: la culpa contractual y la culpa extracontractual o 
aquiliana, de acuerdo con que el reproche tenga una obligación previa preestablecida o que no exista vinculación alguna preexistente. Esta postura es la elegida por autores como Aubry y Rau, Demolombe, Laurent, Saintelectte, Colin y Capitant y Josserand, entre otros.

En el régimen argentino fueron los juristas De Gásperi, Borda, entre otros, quienes adoptaron esta tesitura de la existencia de una dualidad de culpas. Usan como fundamentos de esta nítida separación no sólo su elemento caracterizante, es decir, si había una vinculación preexistente o no, sino que también ven que se diferencian en cuanto a que mientras que la culpa contractual se presume y no necesita ser probada por el acreedor porque es el propio incumplimiento del contrato que hace presumirla. La culpa extracontractual no se presume y debe ser probada por el acreedor. Asimismo, explican como fundamento de la dualidad que sostienen que mientras que en las obligaciones contractuales es necesaria la constitución en mora del deudor, en lo extracontractual - en cambio- el deber de indemnizar surge por la fuerza misma del hecho culposo, sin necesidad de interpelación alguna. Otro punto de divergencia lo encuentran en el carácter de la indemnización: en la culpa contractual es resarcitorio, en tanto en la culpa extracontractual es sancionatorio. También usan como fundamento de la dualidad que la responsabilidad aquiliana es más amplia que la contractual, puesto que para ser responsable por un hecho ilícito basta la edad de 10 años, en que se adquiere el discernimiento para tales actos (artículos 921 y 1076) en tanto para los actos lícitos y responsabilidad emergente de un incumplimiento contractual, el discernimiento empieza recién a los 14 años (artículos 127 y 921), aunque en general se exija la mayoría de edad. La extensión del resarcimiento es también distinta: en la culpa contractual se indemnizan nada más que las consecuencias inmediatas y necesarias, en tanto que en la culpa extracontractual se indemnizan las consecuencias inmediatas y las mediatas previsibles. Por último lo fundan en diferencias en cuanto al plazo de la prescripción.

En el régimen español en ciertos casos (minoritarios) el Tribunal Supremo ha adoptado la dualidad. Es así como ha declarado que la culpa extracontractual excluye a la contractual "por presentar una categoría jurídica contradictoria a esta" (sentencia del 22 de marzo de 1962); que no pueden confundirse ambas categorías, aunque es indudable que se asemejan en lo de producir el efecto de indemnizar (sentencia del 4 de enero de 1929) y sobre todo en la sentencia del 12 de marzo de 1934 al declarar que es preciso distinguir en el derecho tres clases de culpa, de carácter y finalidad distintas y de independencia tan marcada que no pueden confundirse porque el legislador las ha diferenciado claramente: la culpa contractual, definida en el artículo 1101 del Código Civil, nacida de una acción u omisión voluntaria por la que resulta incumplida una obligación anteriormente constituida; la culpa extracontractual a que se refieren los artículos 1902 y ss. , que 
sin antecedente de estipulación alguna produzca un daño o perjuicio por acción u omisión culpable solo civilmente y la culpa nacida del acto delictivo.

B) Unidad de culpas (una culpa, dos regímenes): esta concepción entiende que la culpa es una idea unívoca que se aplica en el mismo sentido en el ámbito de los contratos o de los hechos ilícitos: siempre supone la violación de una obligación preexistente, que será la concreta y precisa definida o la genérica de obrar con diligencia y prudencia que contempla y sanciona la ley. Esta postura es la sostenida esencialmente por Planiol y sus discípulos.

En el Derecho argentino fue la postura adoptada por Lafaille, Colmo, Salas, Orgaz, Morello, Mosset Iturraspe, Carreras y Busso.

El maestro Trigo Represas (1992) nos explicaba que tanto en la culpa contractual como en la extracontractual hay incumplimiento de una obligación preexistente, nada más que en un caso se trata de una obligación contractual y en el otro de un deber legal, y en los dos casos existe el deber de resarcir. Las diferencias que puedan darse en el régimen jurídico de una y otra no bastan para cambiar su naturaleza. Se trata simplemente de variantes en las apreciaciones prácticas perfectamente posibles en un instituto jurídico sin que, por ello, se fraccione su esencia misma.

En el derecho español es la postura que mayoritariamente ha prevalecido. El Tribunal Supremo ha propugnado el criterio de unidad de concepto, es así que ha declarado que los artículos 1101 y 1902 del Código Civil Español sancionadores respectivamente de la culpa contractual y de la extracontractual, responden a un principio común de derecho y a la misma finalidad reparadora comprendida en el concepto genérico que a la de indemnizar asigna el artículo 1106 del Código Civil. Más recientemente, en la sentencia 661/2017 del 12 de diciembre de 2017, Rec. 1955/2015 ha expresado que

La yuxtaposición de las responsabilidades contractual y extracontractual y la teoría de la unidad de la culpa civil no permiten calificar de contractual o de extracontractual la relación jurídica alegando que en la audiencia previa se calificó de contractual lo que en la demanda se dijo era extracontractual sin practicar prueba alguna.

El Tribunal Superior español ha distinguido reiteradamente la culpa contractual de la extracontractual. La sentencia del 3 de mayo de 1968 declara de una manera general que la culpa consiste, bien en la omisión voluntaria, pero realizada sin malicia de la diligencia en las relaciones humanas, mediante cuya aplicación podría haberse evitado un resultado contrario a derecho y no querido -culpa extracontractual - o bien en la acción u omisión voluntaria, asimismo, realizada sin 
malicia que impide el cumplimiento normal de una obligación —culpa contractual-. La primera representa un daño causado con independencia de toda relación jurídica precedente entre las partes, salvo el deber genérico, común a todos los hombres del alterum non laedere. La segunda presupone una relación preexistente - generalmente un contrato- entre el autor del daño y la víctima del daño y todo ello, no es obstáculo para que se haya hablado de un principio único de culpa, principalmente para aplicar a la responsabilidad extracontractual la teoría de la culpa contractual. Así, en la sentencia del 24 de marzo de 1952 declaró que los artículos 1101 y 1902 responden a un principio común de derecho y a la misma finalidad reparadora comprendida en el concepto genérico que a la de indemnizar asigna el artículo 1106 del Código Civil. La sentencia del 23 de diciembre de 1952 declaró que el artículo 1104, aunque está dictado para los casos de culpa contractual es aplicable a todo género de obligaciones y la del 8 de julio de 1972 insiste en aplicar la teoría de la culpa contractual al ámbito extracontractual.

C) Posición intermedia: Bonnecasse (1998) ha creído posible conciliar ambas posiciones doctrinarias, argumentando que la teoría de la unidad de la culpa es exacta si se la juzga teóricamente en abstracto, en su aspecto formal, o sea como la violación de una obligación y su consecuente responsabilidad. En cambio, la teoría de la pluralidad es acertada si se la juzga en sus aplicaciones concretas, pues es indudable que a la culpa contractual y a la extracontractual se les da diferente tratamiento legal. Esta opinión es compartida por Salvat (1958), Llambías (2012) y Acuña Anzorena (1963). Afirma este último que esta posición intermedia es de la mayoría de los autores modernos: "no habría científicamente dos culpas sino dos regímenes de responsabilidad". En igual sentido el maestro Llambías (2012) nos enseñaba que sin aceptar enteramente los puntos de vista extremos que se han expuesto: la culpa es una noción unívoca que el derecho trata diversamente a través de dos diferentes regímenes de responsabilidad, según que esa culpa sea considerada en la inejecución de los contratos o en la comisión de hechos ilícitos. Hay una sola culpa y un doble régimen de responsabilidad culposa. Esta fue la opinión generalizada, cercana a la unificación pero con la presencia de diferencias inevitables.

\section{Segunda etapa: responsabilidad objetiva}

Las exigencias del mundo moderno comenzaron a dar cuenta de la insuficiencia de que toda responsabilidad esté fundada en el factor de atribución subjetivo, es así como la Teoría Objetiva del Riesgo Creado comenzó a tener cabida y a presentar casos donde la responsabilidad no estaba basada exclusivamente en el principio de la culpa.

En el Derecho argentino, esta teoría surgiría primero en el ámbito del derecho laboral en la Ley de Accidentes de Trabajo № 9.688 y en materia de responsabilidad 
extracontractual a través del Código Aeronáutico (ley 14.307). Asimismo, en 1966 por ley se aprobó “La Convención de Viena sobre Responsabilidad Civil por Daños Nucleares", donde se establece la responsabilidad del explotador por daños nucleares. Es así, que lo aclamado por las nuevas exigencias sociales fue traído en la reforma al Código Civil del año 1968 con la ley 17.711, que incorporó la responsabilidad del dueño o guardián de la cosa por el daño causado por el riesgo de dicha cosa, que funciona al margen de toda idea de culpa.

Armonizando la existencia de la responsabilidad objetiva "al lado" de la originaria responsabilidad subjetiva, en principio se entendió que los fundamentos de la responsabilidad como principio general seguían siendo subjetivos pero - para ciertas situaciones excepcionales - se admitía como principio complementario la noción objetiva del deber de resarcimiento, independiente de toda idea de culpa cuya aplicación se limitaba a los únicos supuestos de daños producidos a consecuencia del empleo de elementos peligrosos o de actividad que amenazan la seguridad de los miembros del cuerpo social.

Establecido así el régimen, la responsabilidad objetiva comienza a tener una mayor utilización práctica pasando a ser la culpa el factor de atribución con menos praxis. Es así como el paradigma cambia y se entendió que cualitativamente ambos factores estaban en pie de igualdad, sin perjuicio que en lo cuantitativo los factores objetivos prevalecían.

En el Derecho español se aprecia en los años 1962 y 1968, una producción legislativa propia de la descodificación para regular sectores de riesgo y de necesario tratamiento separado en el tema de la responsabilidad civil. Se trata de supuestos donde se prevé una responsabilidad objetiva por dos razones fundamentales: bien por la peligrosidad de la actividad llevada a cabo, bien como sistema para garantizar la efectividad de las indemnizaciones previstas en la legislación. Así, en la década de los años sesenta aparecieron los regímenes especiales de la responsabilidad civil: uso y circulación de vehículos a motor, la navegación aérea, protección de consumidores y usuarios, etc. La característica común de todos ellos es la preferencia hacia la objetivación de la responsabilidad.

En el caso de los accidentes de tránsito fue la ley 122/1962 la que sentó las bases de lo que hoy se denomina Derecho de la Circulación. Se enuncia en el artículo 39:

El conductor de un vehículo de motor que con motivo de la circulación cause daño a las personas o a las cosas estará obligado a reparar el mal causado, excepto cuando se pruebe que el hecho fuera debido únicamente a culpa o negligencia del perjudicado, o a fuerza mayor extraña a la conducción o al funcionamiento del vehículo. No se considerarán como casos de fuerza mayor los defectos de éste ni la rotura o fallo de alguna de sus piezas o mecanismos. 
La redacción del mismo significó la superación del régimen romanista de responsabilidad civil con apoyo en el enunciado del artículo 1902 del Código Civil, inadecuado al fin último de la protección de las víctimas. Con ello se instaura un sistema objetivista necesario ante la insuficiencia del patrón jurídico tradicional de la culpa.

Sin embargo, pese a la aparición de la responsabilidad objetiva, no sucedió como en el derecho argentino en donde la misma se comenzó a posicionar en igualdad de posición a la responsabilidad subjetiva y existiendo entre ambos una división totalmente tajante. El jurista español Jaime Santos Briz (1973) explica que la responsabilidad por riesgos no es totalmente identificable con la idea de la responsabilidad sin culpa, aunque sí puede decirse que no es necesario que aquella responsabilidad se base en la culpa del responsable. La culpa no es el fundamento de esta clase de responsabilidad, sino que en contraposición a la tesis clásica, recogida en el axioma "no hay responsabilidad sin culpa", las consecuencias dañosas de ciertas actividades o conductas aun lícitas y permitidas deben recaer sobre el que ha creado a través de las mismas riesgos o peligros para terceros.

En este íter, la responsabilidad por riesgos ha sido equiparada por la doctrina e incluso por proyectos legislativos al principio de la culpa como base de la responsabilidad por daños, considerando dividido en dos partes el derecho de daños: un capítulo para la culpa y otro para la responsabilidad por riesgos. Pero esta responsabilidad objetiva no es totalmente ajena a la idea de culpa y en la pugna establecida por ambos regímenes puede decirse que la culpa ha conservado su preeminencia en España, existiendo un proceso lento para llegar a que ambos tipos de responsabilidad en todas las legislaciones se encuentren en pie de igualdad. La jurisprudencia comenzó a mostrar una inclinación a la doctrina de la responsabilidad por riesgo pero sin declararla en forma radical y sin prescindir de los matices culposos variables en cada caso. En sentencia del 15 de junio de 1967 se dejó asentado que

A impulsos de la doctrina dominante en el ámbito civil por imperativos de la necesidad de reparar los daños causados en el intercambio social de actividades, la jurisprudencia va inclinándose de forma acusada hacia una apreciación cada vez más objetiva de la llamada culpa aquiliana, en virtud de lo cual, sin prescindir de los perfiles subjetivos, lo que todavía es imposible dentro de nuestra norma, pondera de manera fundamental otros factores como: el riesgo inherente a la movilización de determinados elementos, etc., tendencia que cuando sea aceptada por la legislación positiva en sus últimas consecuencias nos llevará a estimar solo el factor de la causalidad física con abstracción del factor psicológico. 
EVOLUCIÓN DE LA RESPONSABILIDAD CIVIL EN EL DERECHO ARGENTINO Y ESPAÑOL

- BELÉN MASCI (PP. 99-116)

https://doi.org/10.24215/25916386e005

\section{Tercera etapa: necesidad de unificación de la responsabilidad civil}

En el derecho argentino, encontrándose los factores de atribución objetivos y subjetivos en pie de igualdad, el eje de la responsabilidad civil argentina cambia y pasa a ser el DAÑO. El desplazamiento de la culpa como eje del sistema acaecido por el cambio de paradigma del siglo XX, hizo perder importancia a los debates en torno a si la culpa era una o existía una culpa contractual y otra extracontractual y el debate se centró en si la responsabilidad es una sola y tiene dos órbitas (contractual y extracontractual) o si hay una responsabilidad contractual versus una responsabilidad extracontractual. La responsabilidad con factores objetivos o subjetivos podía darse así en casos de responsabilidad contractual o extracontractual.

No hay dudas de que el máximo jurista argentino Vélez Sarsfield, siguiendo la tradición romano-germánica, optó por la tesis de la dualidad responsabilidad contractual $v s$. responsabilidad extracontractual, utilizando una metodología que separa dichas aguas nítidamente: se dispone sobre la contractual en la parte de las obligaciones (artículos 506 a 515 y 519 a 522) y regula la responsabilidad contractual entre los artículos 1066 a 1136. El artículo 1107, siguiendo esa línea separativa señalaba: "los hechos o las omisiones en el cumplimiento de las obligaciones convencionales, no están comprendidos en los artículos de este título, si no degeneran en delitos del derecho criminal".

Es así que en esta línea la responsabilidad contractual se diferencia de la extracontractual en diversos puntos: existen en este estadio de la evolución de la responsabilidad, diferencias en cuanto extensión del resarcimiento; prescripción de la acción; constitución en mora; prueba de la culpa; discernimiento del responsable; ley aplicable. Sin embargo, pese a que la elección de la dualidad por nuestro legislador fue un hecho, se comenzó a visualizar y a plantear de manera unánime por la doctrina y la jurisprudencia que la responsabilidad civil es una sola y que la misma tendría dos órbitas distintas: contractual y extracontractual. Basta para dar cuenta de ello que los elementos de la responsabilidad son iguales y que dentro de ambas órbitas pueden generarse diferentes matices precisamente por tener distinta fuente de nacimiento (contrato preestablecido en una y no vinculación en el otro caso).

Se visualizó que los elementos de la responsabilidad civil eran comunes a ambos sistemas, pese a que tengan matices distintivos dentro de los mismos. Los mismos son: $1^{\circ}$ antijuridicidad; $2^{\circ}$ daño; $3^{\circ}$ relación de causalidad entre el daño y el hecho; $4^{\text {o }}$ factores de imputabilidad o atribución legal de responsabilidad. "Muchos de estos elementos estaban legislados solamente entre las reglas de la responsabilidad contractual como por ej. la culpa, otros como el daño, tienen una especie de duplicidad de tratamiento, mientras que la antijuridicidad se encontraba entre las disposiciones de los hechos ilícitos (artículos 1066 y 1067)" (Compagnucci, 1997, 
p. 595). Incluso la doctrina nacional trataba en sus obras a algunos elementos de manera conjunta haciendo las respectivas diferenciaciones por su fuente.

Entendida la responsabilidad como un fenómeno jurídico único con mismos principios e idénticos fines se empezó a plantear la necesidad de unificación de la misma. Hay unidad de naturaleza y en sus efectos. Como dice el profesor Picasso (2011, p. 40) es la identidad de objetivos (resarcir a la víctima) y de estructura (necesidad de que concurran los mismos presupuestos en ambos casos) la que justifica la afirmación de la unidad del fenómeno resarcitorio, y alimenta las iniciativas tendientes a lograr la total unificación de regímenes.

Resultaba visible la necesidad de unificación con la simple pregunta que se hacía el profesor Vázquez Ferreyra (1993, p. 94):

¿Qué diferencia cualitativa o cuantitativa existe, por ejemplo, en el daño sufrido por la pérdida de un animal cuando éste muere a causa de ser atropellado por un automovilista (responsabilidad extracontractual), o cuando muere por una mala curación del veterinario a quien contraté para que lo atienda? ¿Acaso para la víctima el perjuicio —pérdida del animal— no es el mismo?

Además de tener elementos comunes y fines iguales, la necesidad de unificación tenía suma importancia práctica, pues en los casos de responsabilidad dudosos tales como la derivada del transporte oneroso o benévolo, la que es consecuencia de la actividad profesional, la de los hoteleros, la precontractual, etc., se podía optar por un régimen u otro a conveniencia del actor, que por temas del cómputo de la prescripción liberatoria solía ser la contractual.

El Proyecto de Unificación Civil y Comercial de 1987, el Proyecto de 1993, el Decreto del Poder Ejecutivo 468/1992 que surgió casi en simultáneo con el anterior y el Proyecto de Código Civil y Comercial de 1998, haciéndose eco de la necesidad de unificación traen una Teoría General aplicable a ambos sistemas.

En el derecho español, el Profesor Llamas Pombo (2010), postula que la obligación de indemnizar o bien se justifica en la culpa, o bien se basa en el riesgo. No existe, por tanto, un "medio camino" entre ambas. Se trata de una obligación objetiva pura, sin paliativos. Si bien la doctrina moderna encabeza dicho postulado, el Tribunal Supremo muchas veces ha sido y es reacio a reconocer a la responsabilidad objetiva dividida de la responsabilidad por culpa, reconoció por ej. en el caso de la responsabilidad automovilística que se trataba de una responsabilidad cuasi objetiva que en principio quedaba limitada a los daños materiales y luego se reconocería cuando los daños estaban referidos a las personas. Y, asimismo, otra parte de la doctrina (De La Torre Olid, 2007, entre otros) sigue reconociendo que 
EVOLUCIÓN DE LA RESPONSABILIDAD CIVIL EN EL DERECHO ARGENTINO Y ESPAÑOL

- BELÉn MASCI (PP. 99-116)

https://doi.org/10.24215/25916386e005

la tradición y actualidad está asegurada desde la letra de dos preceptos que seguimos considerando principales: el artículo 1101 y el artículo 1902 del Código Civil. Actualmente mayormente se basa el sistema en la culpa la cual se lee en consonancia del principio PRO DAMNATIO. Es así que en el derecho español la víctima es el protagonista del sistema y ya no el daño.

En este estadio de la evolución del derecho español, en donde no hay una superación total de la concepción de los factores de atribución, y no logra ser unánime la separación total de la responsabilidad subjetiva de la objetiva como acontece en régimen argentino, con mayoría que acepta la unidad de la concepción de culpa, los debates giran, asimismo, en torno a si la responsabilidad es una sola con dos órbitas (responsabilidad extracontractual y responsabilidad contractual) - tesis de la unidad - o se trata de dos responsabilidades distintas - tesis de la dualidad-:

1) Tesis de la Dualidad: se funda en a) su distinto origen; b) la capacidad negocial para la validez de la obligación preestablecida, o aquella que la Ley presupone para la imposición de deberes, cuya responsabilidad se exige, por uno u otro motivo; c) con base en el onus probandi de la existencia del ilícito y de su imputabilidad; d) Las cuestiones de competencia.

2) Tesis Unitaria: se basa en que los elementos que necesariamente deben de concurrir para que pueda hablarse de la existencia de responsabilidad civil (contractual o extracontractual) según la Sentencia del Tribunal Supremo (STS) del 19 de mayo del 2011 son los mismos y ellos son: “a) Una acción u omisión ilícita; b) la realidad y constatación de un daño causado; c) la culpabilidad y d) nexo causal entre el primer y segundo requisito". Cuando los daños y perjuicios se produzcan como consecuencia del incumplimiento de una relación contractual, en la que concurra dolo, negligencia o morosidad, estaremos hablando de responsabilidad contractual. Por otro lado, cuando entre el dañador y el perjudicado no hay ninguna relación obligatoria previa estaremos hablando de responsabilidad extracontractual, según la cual, los daños y perjuicios que se produzcan son consecuencia de la vulneración del principio alterum non laedere, no causar daño a otro. Por lo que respecta a su regulación en la Constitución Española, este derecho a la reparación de los daños se encuentra en escasos preceptos, así "se consagra que toda persona tiene un derecho constitucionalmente protegido a no sufrir un daño injusto contra un bien o derecho jurídicamente tutelable, que se manifiesta en la protección de los derechos fundamentales a la vida y a la integridad física y moral (artículo 15 Constitución Española), al honor, a la intimidad y a la propia imagen (artículo 18.1 Constitución Española) y en el derecho a la propiedad privada (artículo 33.1 Constitución Española)". 
Yzquierdo Tolsada (2001), plantea la necesidad de una "moderada" unificación de regímenes, explica que en muchos casos resulta muy complicado determinar en qué ámbito de responsabilidad debemos movernos y llevan a la doctrina más moderna a sugerir un acercamiento entre las dos esferas de la responsabilidad civil. Es así como el mencionado jurista destaca tres bloques de razones a favor de una aproximación entre las dos esferas: a) de orden sustantivo: si se parte de la base de que el objeto de la responsabilidad civil es la indemnización del daño, la distinción entre la responsabilidad contractual y la extracontractual no está justificada. Producido un daño, siempre que le sea imputable a su autor, debe de repararlo, con independencia de que haya acaecido dentro en el marco de una relación contractual o extracontractual. La existencia de dos regímenes tan sustancialmente distintos no está justificado en un estado de las relaciones sociales como el actual, en el que la constante exposición a los riesgos de la vida diaria reclama cada vez una mayor defensa de la persona, por ello, se trata más de una distinción de carácter teórico que práctico, ya que ambos tipos de responsabilidad están pensados para un mismo fenómeno, el resarcimiento del daño. Si indemnizar significa dejar a la víctima en la misma situación en la que se encontraba, podrá haber diferencias en lo accesorio, pero no en los principios rectores. La determinación de la naturaleza contractual o extracontractual del daño, como una simple cuestión de clasificación, no alteraría su unidad, ya que la acción será única: único el petitum (resarcimiento del daño) y única la causa petendi (el hecho productor del daño); b) de orden sistemático: si entre el agente y la víctima media contrato, la responsabilidad solamente es la sanción por el incumplimiento del mismo, precisamente porque una de las partes no cumple se plantea la posibilidad de aplicar la responsabilidad contractual. En cambio, cuando nos planteamos aplicar la responsabilidad extracontractual, entre las partes no existe ningún vínculo, es el hecho dañoso el que genera la obligación poniendo en contacto a las partes. Los autores, al hablar de responsabilidad contractual, no suelen ocuparse de cuestiones que sí tratan cuando abordan el estudio de la responsabilidad extracontractual. En ella se estudian los presupuestos prescritos en el artículo 1902 del Código Civil para que nazca la obligación de resarcir: un acto (acción u omisión), un daño, la relación de causalidad entre el acto y el daño y el factor de atribución o imputación (culpa, dolo, riesgo) que permita imputar el resultado lesivo a un determinado patrimonio. En realidad, estos presupuestos son elementos comunes a ambas modalidades de responsabilidad: la acción u omisión de que se habla en la responsabilidad aquiliana es justo el incumplimiento del contrato en la contractual. Y el artículo 1101 del Código Civil habla también de causalidad, de daños y de culpa, al igual que lo hace el artículo 1902 del Código Civil español; c) de orden práctico: no son pocos los supuestos en los que puede discutirse ante qué tipo de responsabilidad nos encontramos y que, de dar una respuesta u otra, va a depender la aplicación por parte de los tribunales de soluciones absolutamente distintas. Los demandantes que, ante daños que pueden encontrar un difícil tratamiento en la 
esfera contractual, encajan la reclamación en la esfera aquiliana (aunque existe contrato), ya que este régimen es más beneficioso para el perjudicado, o los que, ante una acción extracontractual prescrita, tratan de colorear de contractual lo que no lo es, ya que el plazo de prescripción de la acción de responsabilidad contractual es más amplio que el de la extracontractual.

\section{Recapitulación}

Vemos que en el régimen español, al igual que en el régimen argentino, ambos legisladores basaron a la responsabilidad civil en la culpa lo que inicialmente generó el debate de culpa contractual versus culpa extracontractual o si se trataba de una sola culpa con dos órbitas. Ambos regímenes jurídicos separaron nítidamente la regulación del ámbito contractual del extra contractual. La llegada de la responsabilidad objetiva comenzaría con un cambio de paradigma en donde el eje deja de ser la culpa - en el régimen español reacio aun a ello, ya que en ocasiones le da a la responsabilidad objetiva tintes de culpabilidad y la responsabilidad subjetiva tiene un parámetro tan alto de diligencia que pasa a ser objetiva- y la responsabilidad se centra en el daño en el sistema argentino y el sistema español se basa en la víctima "Principio Pro Damnatio".

En palabras de Llamas Pombo (2010, p. 45): "El Protagonista ahora es la víctima, de manera que la formulación de preceptos nucleares de nuestro sistema de responsabilidad podría ser muy distinta, para señalar que 'todo aquel que sufre un daño antijurídico tiene derecho a ser indemnizado"'.

Llegado a ese punto de la evolución de estos dos regímenes de tradición romano-germánico, el derecho argentino, que desde mi punto de vista venía más avanzado reconociendo a la responsabilidad objetiva "al lado" de la subjetiva sin hesitación, va a dar un paso más adelante con la sanción del nuevo Código Civil y Comercial de la Nación, que entró en vigencia desde Agosto del 2015.

Y digo que va a dar un paso más porque la unificación civil y comercial que conllevó la derogación de la obra magistral de Vélez Sarsfield, haciéndose eco de lo solicitado por los más prestigiosos juristas del país viene a unificar la responsabilidad. Es así que en Argentina la responsabilidad es una sola con dos órbitas (contractual y extracontractual).

\section{Cuarta etapa: unificación de la responsabilidad contractual y extracontractual en Argentina: una deuda del legislador español}

Los ecos de necesidad de unificación de la responsabilidad contractual y extracontractual se hicieron realidad en los distintos proyectos de reforma en Argentina. 
En este sentido el Proyecto de Unificación Civil y Comercial de 1987, el Proyecto de 1993, el Decreto del Poder Ejecutivo 468/1992 que surgió casi en simultáneo con el anterior y el Proyecto de Código Civil y Comercial de 1998 unificaban la responsabilidad trayendo normas comunes para ambas. La realización predicada termina viniendo de la mano del nuevo Código Civil y Comercial de la Nación Argentina, que entró en vigor en agosto del año 2015. En sus fundamentos se estableció que

En materia de reparación y siguiendo a los proyectos anteriores, se recepta la unificación de los ámbitos de responsabilidad contractual y extracontractual. Al respecto, existe uniforme opinión doctrinal que ha sido expresada en distintos encuentros científicos (...). El texto proyectado confiere unicidad al régimen contractual y extracontractual (...). La tesis que se adopta es la unidad del fenómeno de la ilicitud, lo cual no implica la homogeneidad, ya que hay diferencias que subsisten. Con la solución que proponemos se unifican claramente los supuestos que han generado dificultades serias, como ocurre con los daños a la persona en el ámbito de la responsabilidad contractual (ej. responsabilidad médica).

De esta manera el nuevo cuerpo normativo cumplió un anhelo largamente acariciado por la doctrina nacional y que había sido ya consagrado por los cuatro proyectos de reforma del Código Civil elaborados desde 1987, el Código Civil y Comercial nacional dispuso unificar las órbitas contractual y extracontractual de la responsabilidad civil. Aun cuando, como se verá, no se trata en realidad de una unificación total - pues como se aclara en sus fundamentos, subsisten ciertas particularidades propias de la responsabilidad derivada del incumplimiento de las obligaciones-, lo cierto es que el nuevo Código establece a la responsabilidad como un único fenómeno con dos órbitas distintas. Así, su artículo 1716 dispone: "Deber de reparar. La violación del deber de no dañar a otro, o el incumplimiento de una obligación, da lugar a la reparación del daño causado, conforme con las disposiciones de este Código". Del mismo surge que cualquiera sea la fuente del deber de reparar el daño (la violación del deber general de no dañar - fuente de la responsabilidad "contractual" - , o el incumplimiento de una obligación -fuente de la extracontractual-) la responsabilidad se rige, en principio, por las mismas reglas. Concordantemente, y a salvo las excepciones que luego se mencionarán, las normas que integran el Capítulo I del Título V del Libro Tercero del Código, consagradas a la responsabilidad civil (artículos 1708 a 1780), se aplican indistintamente a la responsabilidad contractual y la extracontractual. De esta manera los elementos de la responsabilidad civil son conceptos unívocos para ambas órbitas, trayendo una única Teoría General de la Obligación.

Como se ha expresado en los fundamentos del Código Civil y Comercial no existe homogeneidad y eso se debe indefectiblemente a que definitivamente no es 
EVOLUCIÓN DE LA RESPONSABILIDAD CIVIL EN EL DERECHO ARGENTINO Y ESPAÑOL

- BELÉn MASCI (PP. 99-116)

lo mismo incumplir una obligación, que violar el deber genérico de no dañar, pues se trata de situaciones jurídicas diferentes.

Lo Unificado: como principio general existe una teoría general de la responsabilidad civil, que se proyecta a todas las situaciones dañosas, o que entrañan el peligro de daño. Los presupuestos de la responsabilidad civil (antijuridicidad, nexo causal, factor de atribución y daño) se predican en ambos campos y conceptualmente con un único significado. Asimismo, particularmente se unifica: a) el plazo de prescripción liberatoria (artículo 2561 CCiv. y Com.); 2) la extensión del resarcimiento, artículo 1726 CCiv. y Com. (conf. Pizarro, en contra Federico A. Ossola); 3) curso de los intereses accesorios a la obligación de reparar (artículo 1748 CCiv. y Com.); 4) daños a la persona (artículos 1757 y 1758 CCiv. y Com.); 5) la legitimación para reclamar la reparación del daño moral (artículo 1737 CCiv. y Com.); 6) régimen aplicable a los casos con pluralidad de responsables (artículo 1751 CCiv. y Com.).

Las diferencias que subsisten: 1) distinción entre el valor de la prestación y los mayores daños; 2) configuración de la antijuridicidad; 3) configuración del factor de atribución; 4) rol del caso fortuito; 5) previsibilidad del daño contractual; 6) ejecución de la obligación por un tercero; 7) edad a la que se adquiere el discernimiento; 8) ley aplicable a los casos con elementos internacionales.

En el régimen español, esta es la gran asignatura pendiente, legislar una Teoría General de aplicación a ambas órbitas de responsabilidad y estableciendo diferencias subsistentes a raíz de la distinta naturaleza de hechos que da origen a una y otra. La Unificación aclamada sería la oportunidad para "unificar", asimismo, todas las legislaciones que el movimiento descodificador ha producido en el derecho español. Este es el punto radical en donde, sin dudas, el derecho español no ha avanzado a la par de la evolución del derecho argentino.

\section{Conclusiones}

Nuestro país cuenta con una legislación de avanzada en materia de responsabilidad civil, habiendo alcanzado un alto grado de unificación de las esferas de los regímenes contractual y extracontractual. Es una deuda del legislador español dar el mencionado paso, para producir la constitucionalización de su derecho privado, generando un sistema de responsabilidad claro para el justiciable y se deje de lado cualquier tipo de zona mixta que genere inseguridad jurídica. Es inconcebible desde mi punto de vista que se pueda hablar en el derecho español de un "concurso de responsabilidad" y que el Tribunal Supremo entienda que el justiciable pueda optar por la responsabilidad (contractual o extracontractual) que otorgue mayores beneficios. Así como resulta absurdo que para pedir la indemnización 
por unos mismos daños sea diferente el régimen jurídico, según se considere que su origen es contractual o extracontractual. Además de que no existe una línea jurisprudencial homogénea sobre la materia. Por eso, o al menos en determinados ámbitos, sería conveniente disponer de un único régimen jurídico que haga perder la relevancia de que los daños se consideren contractuales o extracontractuales. Unificación que podría lograrse sin mayores problemas a través de la homogeneización de ciertas normas sustantivas y procesales, como sucedió en el régimen argentino. La aclamada unificación de las responsabilidades en el régimen español haría que el mismo pase a estar junto con el sistema argentino dentro de los ordenamientos jurídicos de tradición romano-germánica de avanzada excelencia.

\section{Bibliografía}

Acuña Anzorena, A. (1963). Estudios sobre la Responsabilidad Civil. La Plata: Platense.

Bonnecase, J. (1998). Tratado elemental de derecho civil. México: Harla.

Bustamante Alsina, J. (1991). Teoría General de la Responsabilidad Civil, Séptima Edición. Buenos Aires: Abeledo Perrot.

Compagnucci de Caso, R. H. (1997). Manual de Obligaciones. Buenos Aires: Astrea.

De la Torre Olid, F. (2007). La responsabilidad civil por uso y circulación de vehículos de motor (Una visión panorámica para razonar y legitimar el sistema de Responsabilidad Civil). La Ley, № 39 (pp. 1-24), Sección Estudios. España.

Llamas Pombo, E. (2010). Reflexiones sobre Derecho de Daños: Casos y Opiniones. Madrid: La Ley.

Llambías, J. J., Actualizado Patricio Raffo Benegas (2012). Tratado de Derecho Civil. Buenos Aires: Abeledo Perrot.

Martínez, J. P. (2016). Responsabilidad Civil en el Nuevo Código Civil y Comercial. Sus Dilemas. La Plata: Librería Editora Platense.

Ossola, F. (2017). Responsabilidad Civil. Buenos Aires: Abeledo Perrot.

Pascual Estevill, L. (1991). La Responsabilidad Contractual y La Extracontractual, Aquiliana o Delictual. Diario La Ley, tomo 4 (pp. 1-24). España.

Picasso, S. (2011). La Singularidad de la Responsabilidad Contractual. I edición. Buenos Aires: Abeledo Perrot. 
Reglero ampos, F. (2014). Tratado de Responsabilidad Civil. Pamplona (Navarra): Aranzadi.

Salvat, R. (1958). Tratado de Derecho Civil Argentino. Fuente de las Obligaciones. T. IV. Buenos Aires: Tipográfica Editorial Argentina (T.E.A.).

Santos Briz, J. (1973). Derecho Civil. Teoría y Práctica III. Madrid: Revista de Derecho Privado.

Trigo Represas, F. A. y Cazeaux, P. N. (1992). Compendio de Derecho de las Obligaciones. La Plata: Platense.

Vázquez Ferreyra, R. (1993). Responsabilidad por Daños (Elementos). Buenos Aires: Abeledo Perrot.

Yzquierdo Tolsada, M. (2001). Sistema de Responsabilidad Civil Contractual y Extracontractual. Madrid: Dykinson.

Fecha de recepción: 24-03-2019 Fecha de aceptación: 17-09-2019 
